\title{
Emerging trends in polyploidy research
}

\author{
Umesh C. Lavania $^{1,2}$
}

Published online: 5 May 2015

(C) Archana Sharma Foundation of Calcutta 2015

The Key Word 'Polyploidy' (i.e., the presence of more than two chromosome sets/more than two complete genomes in a cell) coined by Winkler in 1916 [25] has lived nearly a Century. Genome sizes in plants are remarkably diverse, with a 2350 -fold range from the smallest $63 \mathrm{Mb}$ (in two species of carnivorous Genlisea, G. aurea ( $2 n=$ approximately 52$)$ and $G$. margaretae $(2 n=$ approximately 40$))$, to the largest 149 $000 \mathrm{MB}$ (in Paris japonica, $2 \mathrm{n}=8 \mathrm{x}=40$ ), divided into $n=2$ to $n=$ aprox. 600 chromosomes [1]. The polyploidy phenomenon has intrigued biologists over the years and many attractive hypotheses have been proposed in an attempt to assign functionality to the increased content of a duplicated genome $[14,19-21]$. With the advent of newer tools of genetic analysis there has been tremendous resurgence of interest in polyploidy research, and several publishers have brought out special issues of the journals / reference books [4, 6, 12, 17, 18, 22, 24].

Chromosome doubling is brought about by endoreduplication/2n gametes/inter-genomic hybridizationall constraining genetic stability. That polyploidy can be induced with chemicals such as Colchicine, was first demonstrated by OJ Eigsti in 1935 cited in Blakeslee and Avery [2]. Genome duplication impedes sexual reproduction and may impact growth and development. A change to tetraploid state nearly doubles the cell volume and enhances cell surface area by about 1.5 times, often facilitating development of larger

Umesh C. Lavania

lavaniauc@yahoo.co.in

Lucknow University, Lucknow, India

2 CSIR-Central Institute of Medicinal and Aromatic Plants, Lucknow 226015, India organs in plants. But in animals there is a tendency to preserve the same body size by reducing the overall number of cells, thus indicating differential effect to polyploidy change across the taxonomic groups [13].

\section{Stebbins and the central tenets of polyploidy in the 1900s}

Perhaps no other single person has contributed more to our understanding of polyploidy than George Ledyard Stebbins, Jr., with publications spanning over 70 years from 1929 to 1999 [21]. Stebbins is considered as an architect of the initial models of polyploid evolution who strongly influenced thinking about polyploidy for over 50 years. He popularized five major themes as the central tenets of Polyploid evolutionary thinking [21] i.e., (i) Polyploids are formed at a moderate frequency in angiosperms, for which he provided an estimate of $\sim 30-35 \%$ of all species, most is through allopolyploidy, (ii) Polyploids for the most part are evolutionary "dead-ends" with limited importance in diversification, (iii) Polyploids are formed via a single origin with limited genetic potential exhibiting high degree of genetic uniformity across individuals, (iv) Genetic buffering, resulting from the combination of multiple parental genomes, leads to low rates of fixation of new mutations in polyploids, (v) Autopolyploidy is extremely rare in nature; it is not a help but a hindrance, and has minor role in plant evolution. His strong views regarding the minor role of autopolyploidy had a huge impact, hindering research into this type of polyploidy for decades, until DA Levin $[10,11]$ emphasized the role of polyploidy in generating novelty at a range of organizational levels and dynamic nature of polyploid genomes. It is now recognized that both allo- and autopolyploidy are common and extremely important in nature [19-21]. 


\section{Whole genome sequencing led to paradigm change}

With the availability of new genetic tools of DNA based markers, In Situ hybridization, DNA sequencing, there has been tremendous resurgence in polyploidy research that have led to a new paradigm of polyploidy replacing much of the Stebbinsian framework. Complete sequencing of the genome of Arabidopsis thaliana, which has a very small genome (thought to be an undoubted diploid owing to low chromosome number -05 pairs and small genome size $-157 \mathrm{Mb}$ ) revealed presence of numerous duplicate genes, suggesting two or three rounds of ancient genome duplication [3, 23]. In fact all of the angiosperm genomes sequenced exhibit evidence of ancient polyploidy events (Comparative Genomics [CoGe] website, http://genomevolution.org/CoGe/), suggesting occurrence of ancient polyplody in Angiosperms $[5,7]$.

\section{Polyploidy, body size and ecological fitness}

An exhaustive study conducted on paired set of diploid vs autopolyploid clones differing for their native metabolites revealed that polyploidy differentially influences body size depending upon the pathway steps involved in the production of native metabolites produced by the plant, i.e., a longer metabolite pathway shall have negative affect on the body size of the derived polyploids [9]. Of course, if the polyploids could be made to behave like diploids vis-à-vis their meiotic behavior i.e., diploidization coupled with high fertility, then such polyploid may facilitate fixation of heterozygosity [8]. Further, based on critical analysis on endangered and invasive plants vis-à-vis numerical chromosome change, it is observed that multiple sets of chromosomes is often associated with plant's vigour and the ability to adapt to different environments. This could enable polyploid plants to be more competitive and potentially invasive in a new environment $[15,16]$.

\section{New paradigm in polyploidy research}

Synthesis of the huge data available has led to believe that polyploidy is common and the polyploid genomes are highly dynamic [21] beyond anything that Stebbins and his contemporaries could have predicted. Polyploidy is ubiquitous in green plants, with all angiosperms and all seed plants being of ancient polyploid origin, and autopolyploidy is quite common having major force in plant evolution. Polyploidy empowers invasive potential enabling their reach to newer ecological niches.

\section{References}

1. Bennett MD, Leitch I. Nuclear DNA amounts in angiosperms: targets, trends and tomorrow. Ann Bot. 2011;107:467-590.

2. Blakeslee AF, Avery AG. Methods of inducing doubling of chromosomes in plants by treatment with colchicine. J Hered. 1937;28: 393-411.

3. Bowers JE, Chapman BA, Ong JR, Paterson AH. Unravelling angiosperm genome evolution by phylogenetic analysis of chromosomal duplication events. Nature. 2003;422:433-8.

4. Chen ZJ, Birchler JA, editors. Polyploid and hybrid genomics. New York: Wiley; 2013.

5. Comparative Genomics [CoGe] website, http://genomevolution. org $/ \mathrm{CoGe} /$.

6. Greilhuber J, Dolezel J, Wendel J, editors. Plantgenomediversity, vol. 2. Vienna: Springer; 2013.

7. Jiao Y, Wickett NJ, Ayyampalayam S, Chanderbali AS, Landherr L, Ralph PE, et al. Ancestral polyploidy events in seed plants and angiosperms. Nature. 2011;473:97-102.

8. Lavania UC. Polyploidy, body size, and opportunities for genetic enhancement and fixation of heterozygosity in plants. Nucleus. 2013;56:1-6. doi:10.1007/s13237-013-0075-7.

9. Lavania UC, Srivastava S, Lavania S, Basu S, Misra NK, Mukai Y. Autopolyploidy differentially influences body size in plants, but facilitates enhanced accumulation of secondary metabolites, causing increased cytosine methylation. Plant J. 2012;71:539-49.

10. Levin DA. Polyploidy and novelty in flowering plants. Am Nat. 1983;122:1-25.

11. Levin DA. The role of chromosomal change in plant evolution. New York: Oxford University Press; 2002.

12. Lewis WH, editor. Polyploidy. Biological relevance. New York: Plenum Press; 1980.

13. Mable B. Breaking down taxonomic barriers in polyploidy research. Trends Plant Sci. 2003;8:582-90.

14. Madlung A. Polyploidy and its effect on evolutionary success: old questions revisited with new tools. Heredity. 2013;110:99-104. doi: 10.1038/hdy.2012.79.

15. Pandit MK, Pocock MJO, Kunin WE. Ploidy influences rarity and invasiveness in plants. J Ecol. 2011;99:1108-15.

16. Pandit MK, White S, Pocock MJ. The contrasting effects of genome size, chromosome number and ploidy level on plant invasiveness: a global analysis. New Phytol. 2014;203:697-703.

17. Parisod C, Holderegger R, Brochmann C, editors. Plant polyploidy. Evolutionary consequences of autopolyploidy. Special journal issue-New Phytol. 2010;186(1).

18. Soltis PS, Soltis DE, editors. Polyploidy and genome evolution. Berlin: Springer; 2014. p. 415.

19. Soltis DE, Soltis PS, Tate JA. Advances in the study of polyploidy since plant speciation. New Phytol. 2004;161:173-91.

20. Soltis DE, Soltis PS, Schemske DW, Hancock JF, Thompson JN, Husband BC, et al. Autopolyploidy in angiosperms: have we grossly underestimated the number of species? Taxon. 2007;56:13-30.

21. Soltis DE, Visger CJ, Soltis PE. The polyploidy revolution then... and now: Stebbins revisited. Am J Bot. 2014;101:1057-78. doi:10. 3732/ajb.1400178.

22. Special journal issue. Trends in Polyploidy Research in Animals and Plants. Cytogenet Genome Res. 2013;40.

23. Vision TJ, Brown DG, Tanksley SD. The origins of genomic duplications in Arabidopsis. Science. 2000;290:2114-7.

24. Wendel J, Greilhuber J, Dolezel J, Leitch I, editors. Plantgenomediversity, vol. 1. Vienna: Springer; 2012.

25. Winkler $H$. Über die experimentelle erzeugung von pflantzen mit abweichenden chromosomenzahlen. Z Bot. 1916;8:417-531. 